\title{
Gnomoniopsis castaneae associated with Dryocosmus kuriphilus galls in chestnut stands in Sardinia (Italy)
}

\author{
Salvatore Seddaiu ${ }^{(1)}$, \\ Anna Cerboneschi ${ }^{(1)}$, \\ Clizia Sechi ${ }^{(1)}$, \\ Antonietta Mello( ${ }^{(2)}$
}

\begin{abstract}
Invasive fungal pathogens and pests of sweet chestnut (Castanea sativa Mill.) forests drastically reduce their productivity. The recently described Gnomoniopsis castaneae is one of the main agents involved in the epidemic of brown rot of chestnut nuts worldwide. In 2014, during an investigation aimed at evaluating the health status of chestnut forests in Sardinia, a high incidence of necrotic galls induced by the Asian gall wasp Dryocosmus kuriphilus Yasumatsu (Hymenoptera, Cynipidae) was observed. Several fungal isolates were consistently isolated from necrotic gall tissues. Based on their morphological characters and analyses of both the ITS and EF1-a-coding gene sequences, all isolates were identified as Gnomoniopsis castaneae.
\end{abstract}

\section{Keywords: Galls Necrosis, Brown Nut Rot, Invasive Pests, Forest Pathogens}

lations are located in the western area of the Gennargentu Mountain, with about 2239 hectares (INFC 2005). Actions for sustainable territorial development of stakeholders allowed the revival of many recovery and promotional initiatives. The Sardinian government supported such actions by funding a regional program based on the principles of multi-functionality of this forest ecosystem (http://www.regione.sar degna.it/documenti/1 274 20121023092725 .pdf). Several actions have been undertaken to improve the management of chestnut orchards and to tackle phytosanitary problems, including trunk injection of potassium phosphite to control ink disease (Gentile et al. 2009) and spread of hypovirulence of C. parasitica to control chestnut blight (Turchetti et al. 2008).

Nonetheless, chestnut forests in Sardinia have been infested by the Asian gall wasp Dryocosmus kuriphilus Yasumatsu (Hymenoptera (ynipidae), as in many other parts of Italy (Brussino et al. 2002, Graziosi \& Santi 2008). The chestnut gall wasp is native to northern China and it is considered one of the most important pests of chestnut worldwide, causing significant damage to European chestnut, as well as to the
(1) Cork and Silviculture Research Service, Agris Sardegna, v. Limbara 9, I-07029 Tempio Pausania (Italy); (2) Institute for Sustainable Plant Protection, SS Torino - CNR, v.le Mattioli 25, I-10125 Torino (Italy)

@ Antonietta Mello (antonietta.mello@ipsp.cnr.it)

Received: Mar 21, 2016 - Accepted: Nov 27, 2016

Citation: Seddaiu S, Cerboneschi A, Sechi C, Mello A (2017). Gnomoniopsis castaneae associated with Dryocosmus kuriphilus galls in chestnut stands in Sardinia (Italy). iForest 10: 440-445. - doi: 10.3832/ifor2064-009 [online 2017-03-24]

Communicated by: Alberto Santini susceptible eurojapanese hybrids (EPPO 2005). Dryocosmus kuriphilus is a quarantine pest and is included in the $\mathrm{A} 2$ list of the European and Mediterranean Plant Protection Organization (EPPO 2015). It is a univoltine species that reproduces by parthenogenesis. Adults, all females, emerge in the early summer and lay eggs in the buds of the host plant. The eggs hatch soon after, but larval growth begins at budbreak the following spring, when the larvae induce the rapid formation of stem, petiole, and leaf galls. Galling prevents normal shoot growth and fruiting (Kato \& Hijii 1997, Turchetti et al. 2012). In Europe, the insect was first observed in 2002 in Italy (Brussino et al. 2002). In Sardinia it was reported in 2007, whereas on the basis of collected data its introduction probably occurred between 2003 and 2005 by seedlings from Piedmont nurseries (Pantaleoni et al. 2007). Since 2009, biological control of populations of the Asian chestnut gall wasp has been performed using the natural enemy Torymus sinensis Kamijo (Loru et al. 2014). On the basis of experiences carried out in Italy (Quacchia et al. 2008, Panzavolta et al. 2013), the use of natural enemies for the biological control of D. Kuriphilus, besides the prevention of chestnut stand degradation and abandonment during the long delay period before the parasitoid is effective, resulted in a successful reduction of pest population. Investigations on gall development induced by $D$. kuriphilus on Castanea sativa provide indications of the critical time periods for the management of the pest and its effective control (Reale et al. 2014).

Several fungal species have been associated with necrotic galls of $D$. kuriphilus, including Fusarium and Alternaria species (Addario \& Turchetti 2011, Tosi et al. 2015). Species in the Colletotrichum genus have been reported causing extensive larval 
mortality of D. kuriphilus (Gaffuri et al. 2015, Graziosi \& Rieske 2015). Recently, necrosis on galls of $D$. kuriphilus and insect's death have been associated with a Gnomoniopsis sp. (Magro et al. 2010, Vannini et al. 2014)

The possibility of using these fungal species as biocontrol agents against $D$. kuriphilus and evaluating their impacts on plants and animals, is considered an alternative to natural enemies (Addario \& Turchetti 2011, Tosi et al. 2015). However, the genus Gnomoniopsis is found as endophyte in healthy plants, but also behaves as pathogen infecting branches, leaves and chestnut fruits (Visentin et al. 2012, Maresi et al. 2013, Shuttleworth et al. 2013, Dennert et al. 2015, Pasche et al. 2016).

In 2014, during an investigation aimed at evaluating the health status of chestnut forests in Sardinia, galls with black lesions on the exterior and often with a slight depression were observed, suggesting a possible involvement of the above mentioned fungal pathogens.

The aim of this study was to isolate and identify the fungi associated with necrosis of $D$. kuriphilus galls in chestnut areas of Sardinia. To this end, the fungal species isolated from these galls were characterized using both morphological and molecular methods. The fungus most consistently isolated, Gnomoniopsis castaneae, was identified as the most likely agent of the necrosis associated with $D$. kuriphilus galls.

\section{Materials and methods}

\section{Study sites and sampling}

Chestnut stands were selected in spring 2015 in two villages, Aritzo and Belvì (Nuoro province) located in the Sardinian region of "Barbagia di Belvì", on the basis of the high presence of galls induced by $D$. kuriphilus. Two sites per village were selected (Tab. 1) and for each site sampling was undertaken on five chestnut trees, including one central tree and the four most adjacent trees radially. For each tree, 10 symptomatic and 5 asymptomatic galls were collected at the end of June 2015 from both twigs and leaves. The samples were collected from random locations in each tree, bagged and labeled with an identification code and collection date, and stored in the laboratory at $4{ }^{\circ} \mathrm{C}$ for subsequent analysis.

Tab. 1 - Main data station of survey sites.

\begin{tabular}{lcccc}
\hline Site & Aritzo (A1) & Aritzo (A2) & Belvì (B1) & Belvì (B2) \\
\hline Elevation (m a.s.l.) & 890 & 990 & 936 & 910 \\
\hline Exposure & North & North-West & North-East & North-East \\
\hline Morphology & Hill & Hill & Hill & Hill \\
Slope\% & 20 & 15 & 10 & 5 \\
Substrate & Schists & Schists & Schists & Schists \\
Crop & Chestnut-Hazel & Chestnut-Hazel & Chestnut & Chestnut \\
Management & Coppice & High Forest & High Forest & High Forest \\
Geographic & $39^{\circ} 56^{\prime} 57.87^{\prime \prime} \mathrm{N}$ & $39^{\circ} 56^{\prime} 55.78^{\prime \prime} \mathrm{N}$ & $39^{\circ} 58^{\prime} 20.32^{\prime \prime} \mathrm{N}$ & $39^{\circ} 58^{\prime} 34.87^{\prime \prime} \mathrm{N}$ \\
Coordinates & $09^{\circ} 11^{\prime} 23.21^{\prime \prime} \mathrm{E}$ & $09^{\circ} 11^{\prime} 45.12^{\prime \prime} \mathrm{E}$ & $09^{\circ} 09^{\prime} 41.04^{\prime \prime} \mathrm{E}$ & $09^{\circ} 09^{\prime} 32.64^{\prime \prime} \mathrm{E}$ \\
\hline
\end{tabular}

for isolate A1P1GSo; LT593845 as representative of isolates $\mathrm{A}_{2} \mathrm{P}_{4} \mathrm{GSO}, \mathrm{B}_{1} \mathrm{P}_{2} \mathrm{GSO}$, $\mathrm{B}_{2} \mathrm{P} 5 \mathrm{GSO}, \mathrm{A} 2 \mathrm{P} 4 \mathrm{GSO}$; LT593847 for isolate B2P2GSo; LT593846 as representative of isolates $\mathrm{B}_{2} \mathrm{P}_{1} \mathrm{GSO}, \mathrm{A}_{1} \mathrm{P}_{2} \mathrm{GAO}, \mathrm{A}_{2} \mathrm{P}_{3} \mathrm{GSO}$, A1P5GSo, A2P5GSo, B2P5RSo, A1P1RSo. Accession number for EF1-a-coding gene sequences is: LT593848 as representative of isolates $A 1 P 1 G S 1, B 1 P 1 R S 1, B_{2} P_{5} G S 1$, $A_{1} P_{2} G A 1, B 1 P 2 G S 1$.

Phylogenetic analyses were carried out using the software MEGA version 7 (http:// www.megasoftware.net). Neighbour-joining trees were constructed using Kimura's two-parameter model (Kimura 1980) with 1000 bootstrap replicates, including sequences from other species retrieved from databases.

Sardegna.

For morphological identification, three replicates of each isolate on PDA were incubated at $23{ }^{\circ} \mathrm{C}$ in the dark for 20 days. Colony morphology was characterized by observing its form, margin, surface, growth and colour. Conidia were measured under an illuminated Carl Zeiss light microscope (Carl Zeiss, Standard RA 38, Germany) at $400 \times$ magnification. Standard deviation and length ratio were determined for conidia.

DNA was extracted from mycelium of colonies (Mello et al. 1999). The universal primers ITS1 and ITS4 (White et al. 1990), were used to amplify the ITS-1, 5.8S and ITS-2 regions of the nuclear rDNA. Primers EF1-728F and EF1-1199R (Walker et al. 2010) were used to amplify the EF1-a-coding gene. Successful amplifications were verified by gel electrophoresis at $90 \mathrm{~V}$ for 40 min with $1.5 \%$ agarose gel and $4 \mu \mathrm{l}$ of SYBR Safe. PCR products were purified by Eurogold $^{\oplus}$ Gel Extraction Kit (Euroclone, Pero, Milan, Italy) according to the manufacturer's instructions and sequenced by BMR Genomics Lab (http://www.bmr-genomic s.it). All sequences were identified by querying the GenBank database, using the nucleotide BLAST (https://blast.ncbi.nlm. nih.gov) search option (blastn), available through the National Center for Biotechnology Information and the UNITE online database (http://unite.ut.ee/index.php). Sequence similarity was assessed by Multiple Sequence Alignments using the software Clustal Omega (http://www.clustal.org). Sequences were deposited in GenBank. Accession numbers for ITS sequences are: LT593843 for isolate B1P1RSo; LT593844

\section{Results and discussions}

We isolated mycelia cultures from 200 symptomatic galls and 100 asymptomatic galls in order to identify the fungi associated with necrosis. In $68 \%$ of symptomatic and $34 \%$ of asymptomatic galls collected, we observed all colonies with the same features: woolly and dense mycelium, colour variable from greyish to brown (Fig. 1). Only from $1 \%$ of symptomatic galls, two different fungal agents were isolated (two colonies with the same aspect in one of the two galls and two colonies with another aspect from the other gall). In $12 \%$ of symptomatic and $56 \%$ of asymptomatic galls, no fungus was isolated. The $19 \%$ of symptomatic galls and $10 \%$ of asymptomatic galls resulted contaminated from bacteria. The colonies with the same features isolated from symptomatic and asymptomatic galls were regular in outline and developed in concentric circles. Orange and creamy drops of conidial growth appeared in concentric rings or scattered on the surface of older colonies. Conidia were hyaline, oval, obovoid, pyriform, or curved with an average size $(n=120)$ of $6.5 \pm 0.58 \mu \mathrm{m}(\mathrm{SD}) \times$ $2.2 \pm 0.26 \mu \mathrm{m}$ (length $\times$ width). On the basis of these morphological features, the fungus was identified as a Gnomoniopsis sp. This was confirmed by sequencing the ITS region from 13 isolates and the EF1- $a$ locus from five isolates originated from symptomatic and asymptomatic galls. In order to check the genetic variability of the strains, a multiple sequence alignment was made. Sequence alignments of the ITS region ( 523 bp) and the EF1-a-coding gene (578 bp) showed $99.62 \%$ and $100 \%$ similarity, respectively, across all isolates, suggesting that they belong to the same species. Interestingly, an adenine deletion was shared by four of the isolates, which originated from both village locations. BLAST comparison of the 13 ITS sequences gave very high similarity with G. smithogilvyi (from $99 \%$ to $100 \%, 100 \%$ query coverage) and G. castanea (99\%, but $94 \%$ query coverage) and comparison of the five EF1- $\alpha$-coding gene sequences gave very high similarity $(100 \%$, $100 \%$ query coverage) with G. smithogilvyi and an unknown Gnomoniopsis species. 
Fig. 1 - (a) Necrotic galls infested by Gnomoniopsis castaneae; (b) colony of Gnomoniopsis castaneae on PDA; (c) conidia drops; (d) conidia. Scale bars: $10 \mu \mathrm{m}$.
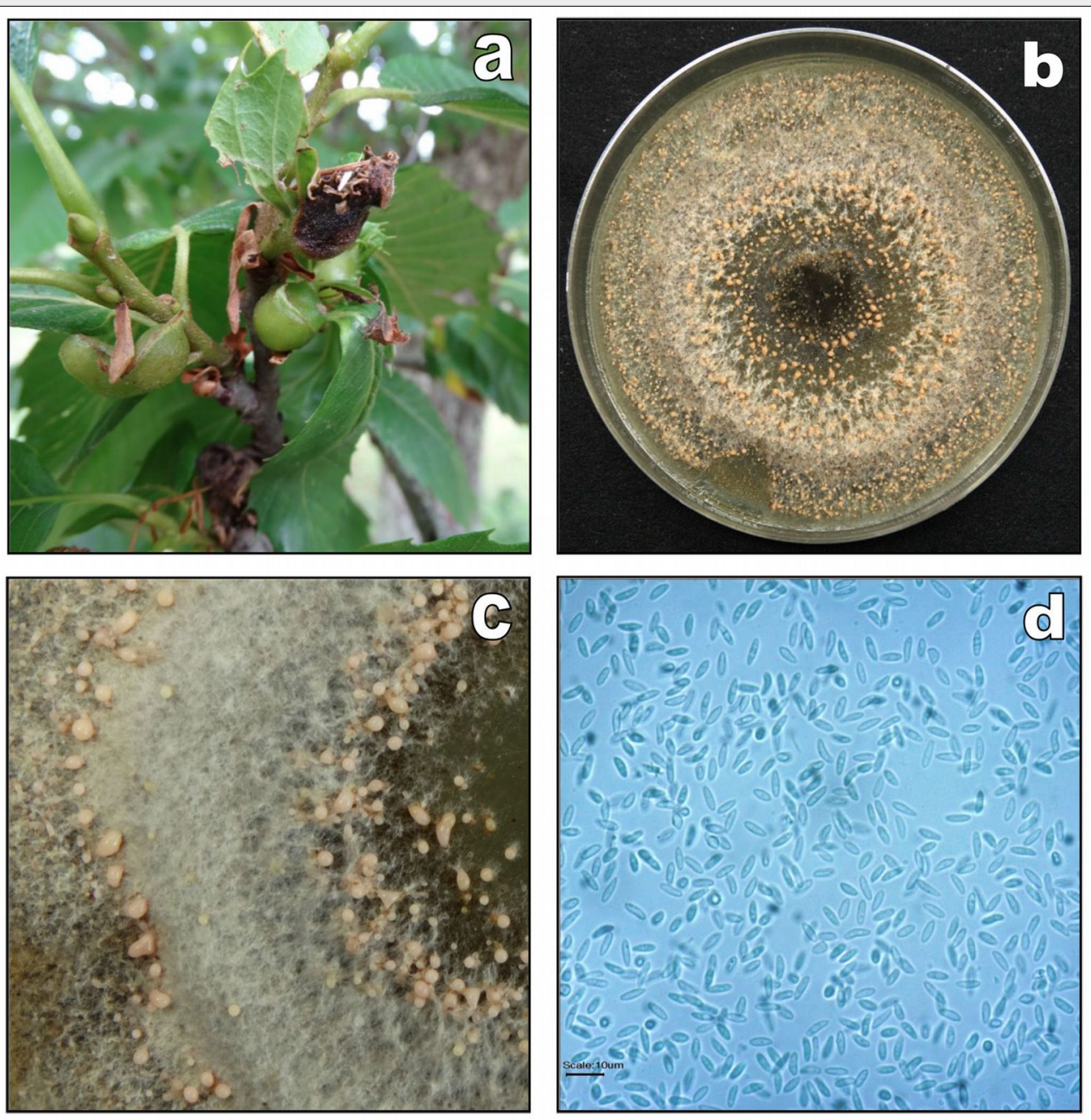

Fig. 2 - Neighbour-joining trees based on a multiple sequence alignment of the ITS region of rDNA (A) and EF1- $\alpha$ locus (B) from fungi isolated in this work and from other fungal species retrieved from GenBank. Apiognomonia veneta was used as outgroup as in Visentin et al. (2012). Soil sample codes: $A 1$ and $A 2$ indicate Aritzo (site 1 and site 2), B1 and $B 2$ indicate Belvì (site 1 and site 2), P1-P5 indicates plant number, GS and GA identify symptomatic and asymptomatic galls, RS identify symptomatic twigs.

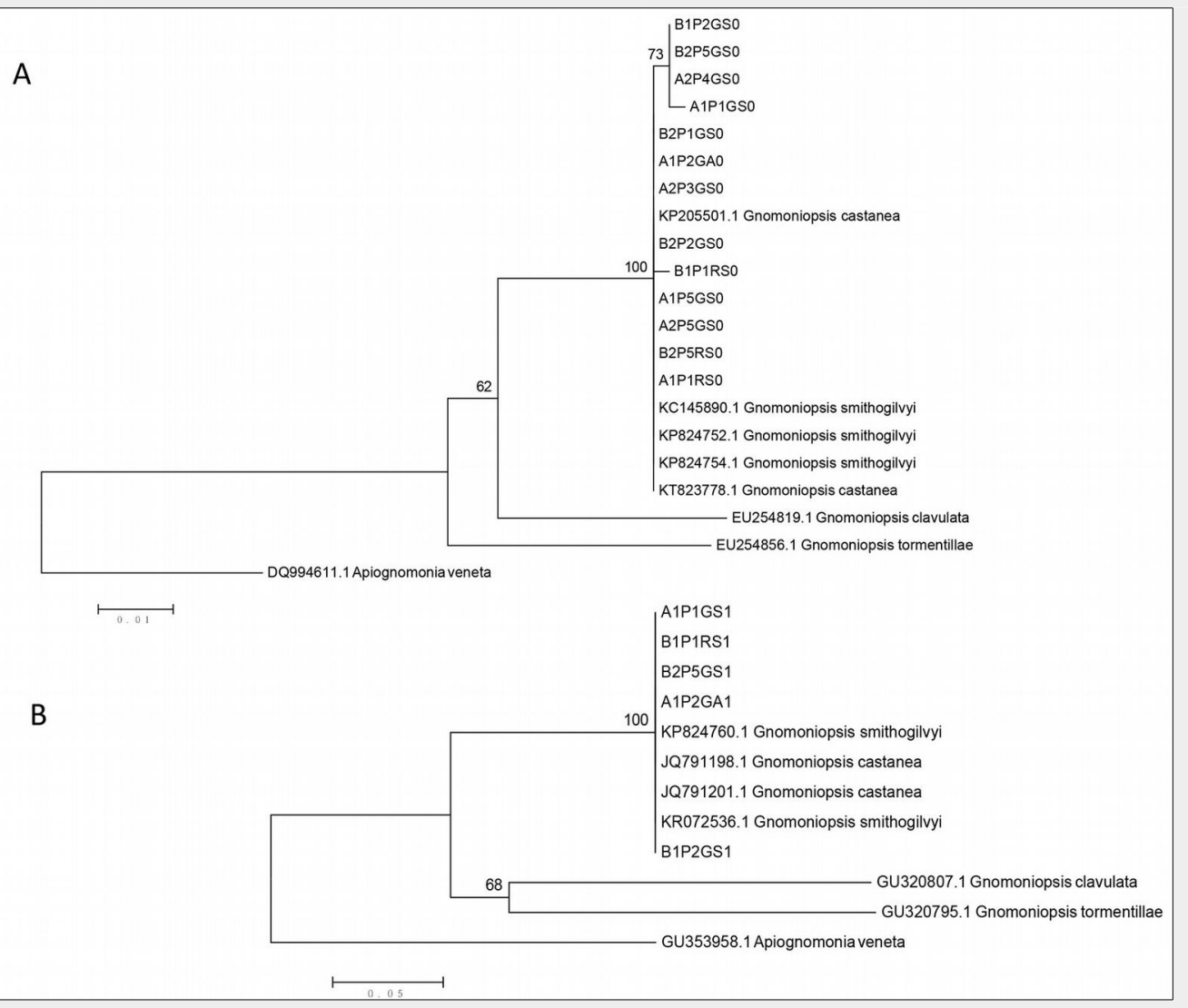


In order to assign our sequences to a taxonomic species, a phylogenetic tree including sequences of $G$. smithogilvyi and $G$. castanea, in addition to sequences of two other species of Gnomoniopsis was built (Fig. 2).

Results for both ITS and EF1-a showed that the fungus consistently isolated in this study clustered together with $G$. smithogilvyi and G. castanea, and separately from the other Gnomoniopsis species G. clavulata and G. tormentillae. In the ITS tree the four isolates sharing the same deletion clustered together with $G$. smithogilvyi and G. castanea. Since G. smithogilvyi and G. castanea are conspecific, as clearly stated by Meyer et al. (2015) and Shuttleworth et al. (2015), and given that Pasche et al. (2016) suggested using the name $G$. smithogilvyi as the agent of the chestnut shoots canker symptoms in Castanea sativa, we can conclude that the causal agent of the necrosis associated with $D$. kuriphilus galls in the chestnut areas located in the "Barbagia di Belvi" region of Sardinia is G. smithogilvyi. However, according to Tamietti (2016), since G. castaneae ("castanea") was described and published earlier than G. smithogilvyi, the legitimate name of the fungus is G. castaneae ("castanea"). For this reason hereafter we follow this rule to indicate the agent of the chestnut shoots canker symptoms in Castanea sativa.

The finding of $G$. castaneae on both symptomatic and asymptomatic galls suggests that this fungus may behave as both endophyte and pathogen. Endophytes are known to produce pathogenic lesions on cynipid galls and interact with gall-forming insects (Wilson 1995).

In this study, we started to evaluate whether chestnut gall necrosis can affect the vitality and emergence of $D$. kuriphilus and parasitoids, in Sardinia. The rates of living larvae (unidentified species) as well as pupae and adults of $D$. kuriphilus, recovered inside necrotic and asymptomatic galls, were statistically compared. In addition, some observations on adult emergence of $D$. kuriphilus and parasitoids from necrotic galls were conducted. Preliminary data showed no adverse effects of gall necrosis on insect vitality. However, the number of chestnut gall samples used so far for vitality test was too small and further more accurate surveys are required to obtain reliable results. In this context, Lione et al. (2016) reported a large number of living adults inhabiting galls colonized by $G$. castaneae and a large number of emerged D. kuriphilus, suggesting that an interaction between insect and fungus can occur during the insect development. By contrast, Vannini et al. (2016) reported a relevant mortality of gall wasp before the adult flight period, suggesting $G$. castaneae as one of the most efficient sources of natural biological control of D. kuriphilus in Europe. It should be considered that, the impact of endophytic fungi on gall wasp vitality is correlated with structural gall traits that vary significantly according to geographic location and development phase (Cooper \& Rieske 2010).

The two additional fungal agents we isolated were identified as Fusarium lateritium and Cladosporium sp. Fusarium lateritium is a plant pathogen, reported as the causal agent of nut gray necrosis on hazelnut (Vitale et al. 2011). Addario \& Turchetti (2011) also isolated Fusarium from necrotic galls.

Gnomoniopsis castaneae has recently been reported in Sardinia as a weak pathogen on hazelnuts that grows in the same area of chestnut forests (Linaldeddu et al. 2016). According to Lione et al. (2016) the infestations of $D$. kuriphilus could have increased the pathogen spreading ability. On the basis of these works we propose two possible scenarios on the diffusion of $G$. castanea in Sardinia after its introduction: (i) it may be widespread from chestnut on the hazelnut without producing disease on this host; (ii) it was already present on hazelnut as weak pathogen and then has infested chestnut trees after gall wasp invasion. Considering that Sardinia chestnut forests are totally isolated from the Italian chestnut range, the relationship between host and pathogen could have different performances compared to the continental case. However, often the lack of data on host or pathogen diversity and biogeography makes it difficult to say whether a disease has been favored by changing environmental conditions and does not yield reliable conclusions on the host-pathogen relationship (Desprez-Loustau et al. 2016). Recently, problems never observed before on the quality of chestnut productions have been reported by the local population. Chestnut forests are very important for local economy because of both fruits and timber productions in rural areas of Sardinia. G. castanea is currently considered the main agent of nut rot (Visentin et al. 2012, Dennert et al. 2015, Lione et al. 2015). The presence of $G$. castaneae in Gennargentu Mountain ecosystems could, therefore, represent a danger in chestnut productions. Furthermore, since Gnomoniopsis spp. exist as endophytes in healthy host plants (Maresi et al. 2013, Dennert et al. 2015) and the European system of plant biosecurity is based principally on visual inspections for symptoms, it is difficult to detect pathogens in asymptomatic plants (Jung et al. 2016) and therefore, the risk of G. castaneae spreading with visually healthy host plants is very high.

This is the first investigation on presence of $G$. castaneae infecting chestnut cynipid galls in Sardinia. Future research is needed to deeper analyse the interaction between $D$. kuriphilus and $G$. castaneae and to understand how this fungus can affect the health status of Mediterranean chestnut ecosystems and then, the quality of their products. The availability of specific primers (Lione et al. 2015) will help to fast monitor the presence of $\mathrm{G}$. Castaneae in these ecosystems.

\section{Acknowledgements}

The authors would like to thank Sarah Green (Forest Research, Scotland) for her kindly help to English language editing. We thank Giuseppe Manconi, Giovanni Maria Mureddu and Giovanni Antonio Puliga for technical assistance. This research was funded by the Sardinian Regional Government's Department of Environmental Protection.

\section{References}

Addario E, Turchetti T (2011). Parasitic fungi on Dryocosmus kuriphilus in Castanea sativa necrotic galls. Bulletin of Insectology 64: 269273. [online] URL: http://www.bulletinofinsec tology.org/pdfarticles/vol64-2011-269-273addar io.pdf

Borghetti M, Menozzi P, Vendramin GG, Giannini R (1986). Morphological variation in chestnut fruits (Castanea sativa Mill.) in Tuscany (Italy). Silvae Genetica 35: 124-128. [online] URL: http://sites.google.com/site/marcoborghetti195 8/Morphologicalvariation.pdf

Brasier CM (2008). The biosecurity threat to the UK and global environment from international trade in plants. Plant Pathology 57: 792-808. doi: 10.1111/j.1365-3059.2008.01886.x

Brussino G, Bosio G, Baudino M, Giordano R, Ramello F, Melika G (2002). Pericoloso insetto esotico per il castagno europeo [A dangerous exotic insect threatening European chestnut]. Informatore Agrario 37: 59-61. [in Italian]

Camarda I, Valsecchi F (2008). Alberi e arbusti spontanei della Sardegna [Trees and shrubs spontaneous of Sardinia]. Carlo Delfino Editore, Sassari, Italy, pp. 480. [in Italian]

Cooper WR, Rieske LK (2010). Gall structure affects ecological associations of Dryocosmus kuriphilus (Hymenoptera: Cynipidae). Environmental Entomology 39: 787-797. - doi: 10.1603/ ENo9382

Dennert F, Broggini G, Gessler C, Storari M (2015). Gnomoniopsis castanea is the main chestnut nut rot agent in Switzerland. Phytopathologia Mediterranea 54: 41-53. [online] URL: http://www.fupress.net/index.php/pm/art icle/view/14712

Desprez-Loustau ML, Aguayo J, Dutech C, Hayden KJ, Husson C, Jakushkin B, Marçais B, Piou D, Robin C, Vacher C (2016). An evolutionary ecology perspective to address forest pathology challenges of today and tomorrow. Annals of Forest Science 73: 45-67. - doi: 10.1007/s1359 5-015-0487-4

EPPO (2005). Data sheets on quarantine pests: Dryocosmus kuriphilus. EPPO Bulletin 35: 422424. - doi: 10.1111/j.1365-2338.2005.00849.x

EPPO (2015). EPPO database on quarantine pests. European and Mediterranean Plant Protection Organization, Web site. [online] URL: http://www.eppo.int/QUARANTINE/listA2.htm Gaffuri F, Maresi G, Pedrazzoli F, Longa CMO, Boriani M, Molinari M, Tantardini A (2015). Colletotrichum acutatum associated with Dryocosmus kuriphilus galls on Castanea sativa. Forest pathology 45: 169-171. - doi: 10.1111/efp.12178 Gentile S, Valentino D, Tamietti G (2009). Control of ink disease by trunk injection of potassium phosphite. Journal of Plant Pathology 91: 565571. [online] URL: http://www.jstor.org/stable/ 
41998673

Graziosi I, Rieske LK (2015). A plant pathogen causes extensive mortality in an invasive insect herbivore. Agricultural and Forest Entomology 17: 366-374. - doi: 10.1111/afe.12116

Graziosi I, Santi F (2008). Chestnut gall wasp (Dryocosmus kuriphilus): spreading in Italy and new records in Bologna province. Bulletin of Insectology 61: 343-348. [online] URL: http:// www.researchgate.net/publication/237304768 INFC (2005). Inventario Nazionale delle Foreste e dei Serbatoi Forestali di Carbonio [National Inventory of Forests and Forest Carbon Sinks]. Ministero delle Politiche Agricole Alimentari e Forestali, Ispettorato Generale - Corpo Forestale dello Stato, Rome, Italy, Consiglio per la Ricerca e Sperimentazione in Agricoltura Unità di ricerca per il Monitoraggio e la Pianificazione Forestale (CRA-MPF), Trento, Italy, Web site, [in Italian] [online] URL: http://www.sian.it/ inventarioforestale/jsp/01tabelle_superficie.jsp Jung T, Orlikowski L, Henricot B, Abad-Campos P, Aday A.G, Aguín Casal O, Bakonyi J, Cacciola SO, Cech T, Chavarriaga D, Corcobado T, Cravador A, Decourcelle T, Denton G, Diamandis S, Dogmus-Lehtijärvi HT, Franceschini A, Ginetti B, Green S, Glavendekić M, Hantula J, Hartmann $G$, Herrero $M$, Ivic D, Horta Jung $M$, Lilja A, Keča N, Kramarets V, Lyubenova A, Machado H, Magnano di San Lio G, Mansilla Vázquez PJ, Marçais B, Matsiakh I, Milenkovic I, Moricca S, Nagy ZÁ, Nechwatal J, Olsson C, Oszako T, Pane A, Paplomatas EJ, Pintos Varela C, Prospero S, Rial Martínez C, Rigling D, Robin C, Rytkönen A, Sánchez ME, Sanz Ros AV, Scanu B, Schlenzig A, Schumacher J, Slavov S, Solla A, Sousa E, Stenlid J, Talgø V, Tomic Z, Tsopelas P, Vannini A, Vettraino AM, Wenneker $M$, Woodward S, Peréz-Sierra A (2016). Widespread Phytophthora infestations in European nurseries put forest, semi-natural and horticultural ecosystems at high risk of Phytophthora diseases. Forest Pathology 46: 134-163. - doi: 10.1111/efp.12239

Kato K, Hijii N (1997). Effects of gall formation by Dryocosmus kuriphilus Yasumatsu (Hym., Cynipidae) on the grow of chestnut trees. Journal of Applied Entomology 121: 9-15. - doi: 10.1111/j.14 39-0418.1997.tb01363.x

Kimura M (1980). A simple method for estimating evolutionary rate of base substitutions through comparative studies of nucleotide sequences. Journal of Molecular Evolution 16: doi: $10.1007 / B F 01731581$

Lione G, Giordano L, Sillo F, Gonthier P (2015). Testing and modelling the effects of climate on the incidence of the emergent nut rot agent of chestnut Gnomoniopsis castanea. Plant Pathology 64: 852-863 - doi: 10.1111/ppa.12319

Lione G, Giordano L, Ferracini C, Alma A, Gonthier $P$ (2016). Testing ecological interactions between Gnomoniopsis castaneae and Dryocosmus kuriphilus. Acta Oecologica 77: 10-17 - doi: 10.1016/j.actao.2016.08.008

Linaldeddu BT, Deidda A, Scanu B, Franceschini A, Alves A, Abdollahzadeh J, Phillips AJL (2016). Phylogeny, morphology and pathogenicity of Botryosphaeriaceae, Diatrypaceae and Gnomoniaceae associated with branch diseases of hazelnut in Sardinia (Italy). European Journal of Plant Pathology 146: 259-279. - doi: 10.1007/s106 58-016-0912-z

Loru L, Cascone P, Fadda ML, Fois X, Guerrieri E, Pantaleoni RA (2014). Dryocosmus kuriphilus (Hymenoptera Cynipidae) in Sardegna. [Dryocosmus kuriphilus (Hymenoptera Cynipidae) in Sardinia]". In: Proceedings of the "XXIV Congresso Italiano di Entomologia". Orosei (Sardinia, Italy) 9-14 Jun 2014, pp. 132. [in Italian]

Magro P, Speranza S, Stacchiotti M, Martignoni D, Paparatti B (2010). Gnomoniopsis associated with necrosis of leaves and chestnut galls induced by Dryocosmus kuriphilus. Plant Pathology 59 (6): 1171-1171. - doi: 10.1111/j.1365-3059.20 10.02336.x

Maresi G, Oliveira Longa CM, Turchetti T (2013). Brown rot on nuts of Castanea sativa Mill: an emerging disease and its causal agent. iForest 6: 294-301. - doi: 10.3832/iforo952-006

Mello A, Garnero L, Bonfante P (1999). Specific PCR-primers as a reliable tool for the detection of white truffles in mycorrhizal roots. New Phytologist 141: 511-516. - doi: 10.1046/j.1469-8137.19 99.00356.x

Meyer JB, Gallien L, Prospero S (2015). Interaction between two invasive organisms on the European chestnut: does the chestnut blight fungus benefit from the presence of the gall wasp? FEMS Microbiology Ecology 91 (11): fiv122. - doi: 10.1093/femsec/fiv122

Pantaleoni RA, Loru L, Sassu A, Loddo C (2007). Il cinipide del castagno in Sardegna: una nuova preoccupante presenza nella Barbagia di Belvì. [The chestnut gall wasp in Sardinia: a new disturbing presence in Barbagia di Belvì (Sardinia, Italy)]. Notiziario sulla protezione delle piante 21: 203-206. [in Italian]

Panzavolta T, Bernardo U, Bracalini M, Cascone P, Croci F, Gebiola M, lodice L, Tiberi R, Guerrieri E (2013). Native parasitoids associated with Dryocosmus kuriphilus in Tuscany, Italy. Bulletin of Insectology 66: 195-201. [online] URL: http:// s3.amazonaws.com/academia.edu.documents/ 39396509/

Pasche S, Calmin G, Auderset G, Crovadore J, Pelleteret $\mathrm{P}$, Mauch-Mani B, Barja F, Paul B, Jermini $M$, Lefort $F$ (2016). Gnomoniopsis smithogilvyi causes chestnut canker symptoms in Castanea sativa shoots in Switzerland. Fungal Genetics and Biology 87: 9-21. - doi: 10.1016/j. fgb.2016.01.002

Quacchia A, Moryia S, Bosio G, Scapin I, Alma A (2008). Rearing, release and settlement prospect in Italy of Torymus sinensis, the biological control agent of the chestnut gall wasp Dryocosmus kuriphilus. BioControl 53 (6): 829-839. - doi: 10.1007/s10526-007-9139-4

Reale L, Tedeschini E, Rondoni G, Ricci C, Bin F, Frenguelli G, Ferranti $F$ (2014). Histological investigation on gall development induced by a worldwide invasive pest, Dryocosmus kuriphilus, on Castanea sativa. Plant Biosystems 150: 35-42. - doi: 10.1080/11263504.2014.918058

Robin C, Heiniger U (2001). Chestnut blight in Europe: diversity of Cryphonectria parasitica, hypovirulence, and biocontrol. Forest Snow and Landscape Research 76: 361-367. [online] URL: http://www.wsl.ch/dienstleistungen/publikatio nen/pdf/4888.pdf

Santini A, Ghelardini L, De Pace C, Desprez-Loustau ML, Capretti P, Chandelier A, Cech T, Chira D, Diamandis S, Gaitniekis T, Hantula J, Holden- rieder $O$, Jankovsky $L$, Jung $T$, Jurc $D$, Kirisits $T$, Kunca A, Lygis V, Malecka $M$, Marcais $B$, Schmitz S, Schumacher J, Solheim H, Solla A, Szabò I, Tsopelas P, Vannini A, Vettraino AM, Webber J, Woodward S, Stenlid J (2013). Biogeographical patterns and determinants of invasion by forest pathogens in Europe. New Phytologist 197 (1): 238-250. - doi: 10.1111/j.14698137.2012.04364.x

Scanu B, Linaldeddu BT, Franceschini A (2010). First report of Phytophthora pseudosyringae associated with ink disease of Castanea sativa in Italy. Plant Disease 94 (8): 1068. - doi: 10.1094/ PDIS-94-8-1068B

Shuttleworth LA, Liew ECY, Guest DI (2013). Survey of the incidence of chestnut rot in southeastern Australia. Australasian Plant Pathology 42: 63-72. - doi: 10.1007/s13313-012-0170-2

Shuttleworth LA, Walker DM, Guest DI (2015). The chestnut pathogen Gnomoniopsis smithogilvyi (Gnomoniaceae, Diaporthales) and its synonyms. Mycotaxon 130: 929-940. - doi: 10.52 48/130.929

Tamietti G (2016). On the fungal species Gnomoniopsis castaneae ("castanea") and its synonym G. smithogilvyi. Journal of Plant Pathology 98: 189-190.

Tosi L, Beccari G, Rondoni G, Covarelli L, Ricci C (2015). Natural occurrence of Fusarium proliferatum on chestnut in Italy and its potential entomopathogenicity against the Asian chestnut gall wasp Dryocosmus kuriphilus. Journal of Pest Science 88: 369-381. - doi: 10.1007/s10340014-0624-0

Turchetti T, Ferretti F, Maresi G (2008). Natural spread of Cryphonectria parasitica and persistence of hypovirulence in three Italian coppiced chestnut stands. Forest Pathology 38: 227-243. - doi: 10.1111/j.1439-0329.2008.00557.x Turchetti T, Pennacchio F, D’Acqui L, Maresi G, Pedrazzoli $F$ (2012). Interventi per la gestione dei castagneti invasi dal cinipide [Practices to manage chestnut orchards infested by the Chinese gall wasp]. Forest@ 9: 227-235. [in Italian] - doi: 10.3832/eforo701-009

Vannini A, Vettraino AM (2001). Ink disease in chestnuts: impact on the European chestnut. Forest Snow and Landscape Research 76: 345350. [online] URL: http://www.wsl.ch/dienstleis tungen/publikationen/pdf/4859.pdf

Vannini A, Martignoni D, Bruni N, Tomassini A, Aleandri MP, Vettraino AM, Caccia R, Speranza $S$, Paparatti B (2014). New notes on the biology of the chestnut fungus Gnomoniopsis sp. and its possible use as a biocontrol agent of oriental chestnut gall wasp. Acta Horticulturae (ISHS) 1019: 235-238. - doi: 10.17660/ActaHortic. 2014.1019.35

Vannini A, Vettraino AM, Martignoni D, Morales Rodriguez C, Contarini M, Caccia R, Paparatti B, Speranza S (2016). Does Gnomoniopsis castanea contribute to the natural biological control of chestnut gall wasp? Fungal Biology 121 (1): 4452. - doi: 10.1016/j.funbio.2016.08.013 Visentin I, Gentile S, Valentino D, Gonthier P, Tamietti G, Cardinale F (2012). Gnomoniopsis castanea sp. nov. (Gnomoniaceae, Diaporthales) as a causal agent of nut rot in sweet chestnut. Journal of Plant Pathology 94: 411-419. - doi: 10.4454/JPP.FA.2012.045

Vitale S, Santori A, Wajnberg E, Castagnone- 
Sereno P, Luongo L, Belisario A (2011). Morphological and molecular analysis of Fusarium lateritium, the cause of gray necrosis of hazelnut fruit in Italy. Phytopatology 101: 679-686. - doi: 10.1094/PHYTO-04-10-0120

Walker D, Castlebury LA, Rossman AY, Sogonov M, White J (2010). Systematics of the genus
Gnomoniopsis (Gnomoniaceae, Diaporthales) based on a three gene phylogeny, host associations, and morphology. Mycologia 102: 14791496. - doi: 10.3852/10-002

White TJ, Bruns T, Lee S, Taylor J (1990). Amplification and direct sequencing of fungal ribosomal DNA for phylogenetics. In: "PCR Protocols: a guide to methods and applications" (Innis MA, Gelfand DH, Sninsky JJ, White TJ eds). Academic Press, San Diego, CA, USA, pp. 315-322. Wilson D (1995). Fungal endophytes which invade insect galls: insect pathogens, benign saprophytes, or fungal inquilines? Oecologia 103: 255-260. - doi: 10.1007/BFo0329088 